\title{
The effect of a medical opinion on self- perceptions of weight for Mexican adults: perception of change and cognitive biases
}

\author{
Jonathan F. Easton ${ }^{1 *}$, Christopher R. Stephens ${ }^{1,2}$ and Heriberto Román Sicilia ${ }^{1}$
}

\begin{abstract}
Background: This study analysed the relationship between perceived and actual Body Mass Index (BMI) and the effect of a prior identification of obesity by a medical professional for adults using difference in response for two distinct BMI self-perception questions. Typically, self-perception studies only investigate the relation with current weight, whereas here the focus is on the self-perception of weight differences.

Methods: A statistical approach was used to assess responses to the Mexican ENSANUT 2006 survey. Adults in the range of BMI from 13 to 60 were tested on responses to a categorical question and a figure rating scale selfperception question. Differences in response by gender and identification of obesity by a medical professional were analysed using linear regression.

Results: Results indicated that regardless of current BMI and gender, a verbal intervention by a medical professional will increase perceived BMI independently of actual BMI but does not necessarily make the identified obese more accurate in their BMl estimates. A shift in the average self-perception was seen with a higher response for the identified obese. A linear increase in perceived BMI as a function of actual BMI was observed in the range $\mathrm{BMI}<35$ but with a rate of increase much less than expected if weight differences were perceived accurately.

Conclusions: Obese and overweight Mexican adults not only underestimated their weight, but also, could not accurately judge changes in weight. For example, an increase of $5 \mathrm{~kg}$ is imagined, in terms of self-image, to be considerably less. It was seen that an identification of obesity by a health care professional did not improve ability to judge weight but, rather, served as a new anchor from which the identified obese judge their weight, suggesting that even those identified obese who have lost weight, perceive their weight to be greater than it actually is. We believe that these results can be explained in terms of two cognitive biases; the self-serving bias and the anchoring bias.
\end{abstract}

Keywords: BMl, Obesity, Linear regression, Cognitive biases, Self-perception, Medical Identification, Public Health Survey

\section{Background}

A report from the Food and Agriculture Organization of the United Nations published in 2013 showed that for the first time Mexico has overtaken the USA as the country with the highest obesity rate in the World [1]. At $32.8 \%$, one third of the Mexican population is obese, a figure that increases to approximately $70 \%$ including the overweight [2]. Obesity is a growing problem,

\footnotetext{
* Correspondence: jonoeaston8@hotmail.com

${ }^{1}$ C3-Centro de Ciencias de la Complejidad, Universidad Nacional

Autónoma de México, Circuito Centro Cultural s/n, Ciudad Universitaria,

Col. Universidad Nacional Autónoma de México, Del. Coyoacán, C.P. 04510

Ciudad de México, Mexico

Full list of author information is available at the end of the article
}

affecting all parts of the world [3]. Consequently, obesity has become an important risk factor for the most common causes of death and illness worldwide, surpassing malnutrition and infectious diseases, as highlighted by Kopelman [4]. As obesity is such an important health risk, there are a large number of potential treatments and interventions available, as discussed in various summary articles, for example [5, 6]. However, a key problem, as will be seen here and as has been shown elsewhere [7], is that obesity is a condition frequently not recognised by the obese themselves, thus potentially delaying action, either by the individual or through the advice of a healthcare professional. For instance, although 
the idea of eating less and exercising more is recognised as beneficial, based on previous evidence $[8,9]$ it is apparent that without a consultation with a medical professional, there is a substantially lower probability that an adult will apply, or feel the need to apply, the changes necessary in order to avoid weight gain or lose weight.

A major factor linked to lack of self-awareness about obesity is the systematic bias associated with the selfperception of body weight. The discrepancy between actual and perceived BMI has been extensively reported, with studies from Europe [10], the United States [11-14] and Asia [15]. The main conclusion is that there is a systematic tendency for the overweight and obese to underestimate their actual BMI. Many studies consider how different factors affect the self-perception of BMI, such as level of education and type of student [10], amongst many other factors [16]. Several studies also exist for the Mexican population with differing points of emphasis. Adult-based investigations are mainly divided into separate male and female studies that then include other conditions, including socioeconomic status [17] and age $[18,19]$. Several studies have compared similar groups between Mexico and the United States [20-22]. In these cases, identification of obesity was examined specifically for either obese males or females and for responses to one specific type of self-perception question.

Accepting obesity as a serious condition, it is imperative that people can identify it both in themselves and in others. The potential public health consequences of the misperception of BMI and the inability to recognise obesity in oneself have also been the subject of much discussion [23-27]. In particular, Duncan et al. [23] have shown that the misperception of BMI among overweight and obese adults was associated with less likelihood of interest in, or attempts at, weight loss, and less physical activity. As they point out, their findings are consistent with the Health Belief Model [28], which proposes that a perceived susceptibility to a given condition is necessary to promote appropriate behavioural changes. Thus, correcting perception of weight status may be an important consideration in the design of weight loss interventions. It has also been shown that an identification of obesity by a healthcare professional $[17,29]$ is correlated to a lower degree of misperception of BMI among the overweight and obese. What is not clear, however, is if this leads to better outcomes in terms of weight reduction and/or healthier lifestyles, though there is some evidence that awareness of obesity can have a positive effect [30].

In this paper, we considered the relationship between actual and self-perceived BMI as a function of gender and of a previous identification of obesity by a healthcare professional for a large, representative Mexican adult population, over all BMI and age ranges and for two different forms of self-perception question. The data used in this analysis is associated with the Mexican National Health and Nutrition Survey (ENSANUT) 2006 [31]. This is a nationwide survey containing data from all states in Mexico covering a wide range of topics including social demographics, home life, nutrition, work, education, medical histories and much more.

The principal aim of this paper was to compare the relationships between actual and perceived BMI, as well as BMI differences, using two different self-perception questions: a categorical BMI status question and a selfperception figure rating scale (FRS) question. Further aims were to determine the impact of a consultation identifying obesity with a healthcare professional on perceived BMI, and, finally, to examine the effect of gender.

Based on the studies discussed above [14-20, 27], we hypothesised that body weight is underestimated for a complete population for multiple perception questions and that an intervention from a medical professional can cause a substantial change in self-perception.

\section{Methods}

From the ENSANUT 2006 survey, we took 20360 adults (age 20 or above) with nutritional data as the full data set. Exclusions included any adult with missing data, or responses of 'unknown' and 'don't know' in any of the required variables, such as: height or weight, medically identified obesity and the weight self-perception questions. Adults who had been diagnosed as diabetic were also excluded to ensure that there is no effect on the analysis arising from the strong relation between diabetes and obesity, or from the effect of a medical intervention that is not directly for obesity. Further exclusions were made for those with a BMI outside the range of $13-60 \mathrm{kgm}^{-2}$, these units apply to all occurrences of BMI values throughout this paper. There were no exclusions made based on age. A total of 17009 adults were used for this study. The complete ENSANUT 2006 data has an approximate 2:1 ratio of women to men, within the filtered data in this analysis this ratio was reflected with $63.52 \%$ women and $36.48 \%$ men.

The condition of obesity was self-reported via the question: "Have you ever been told by a healthcare professional that you are obese?" From this point onwards, all references to identification refer to identified as obese by a healthcare professional. On the basis of the response to this question, four main groups based on gender and identification of obesity were constructed: Non-identified (NI) men [5933]; Identified (I) men [272]; Non-identified women [9954]; and Identified women [850]. In each group, all participants may, or may not, actually be obese.

Self-perception of BMI status was assessed using two distinct questions within the ENSANUT 2006 questionnaire [31]. The first was a categorical question, asking 
each individual to select one of four categories best describing their current weight. The options were: Underweight; Normal; Overweight; or Obese. The second question was image-based, using the Stunkard scale [32], as shown in Fig. 1 (ref. [31]). Alternative FRSs exist but the Stunkard 9-figure scale compares favourably to others [33]. This question asked each individual to select which figure best represents him or her at this moment.

For the purpose of comparison of averages for both questions, categories were converted to an ordinal scale as there is a clear size ordering. For the categorical question, we used the scale: underweight $=1$, normal $=2$, overweight $=3$ and obese $=4$. For the Stunkard scale, with figures $1-9$, the standard categorisation is: $1-2=$ underweight, $3-4=$ normal, $5-7=$ overweight and $8-9=$ obese [34].

Actual weight was based on weight and height measurements obtained by trained health technicians to ensure measurement accuracy. BMI was calculated and standard weight categories were constructed. It is important to recognise that as both fat and muscle mass affect weight, it is possible to have a person with increased muscle mass and very little fat report a high BMI. We assume in this paper that for the general adult population BMI provides a good measure of weight and obesity.

In order to create fair comparisons across each of the four previously defined groups by gender and identification, one standardized set of coarse-grained bins was considered to group the data. Eight BMI bins were created with the following ranges: $13 \leq \mathrm{BMI}<25,25 \leq \mathrm{BMI}$ $<27,27 \leq \mathrm{BMI}<29,29 \leq \mathrm{BMI}<30,30 \leq \mathrm{BMI}<35,35 \leq$ $\mathrm{BMI}<40,40 \leq \mathrm{BMI}<45$ and $45 \leq \mathrm{BMI} \leq 60$. The binning was made to adhere to the boundaries of the main BMI cut-offs for underweight, normal, overweight and obese,

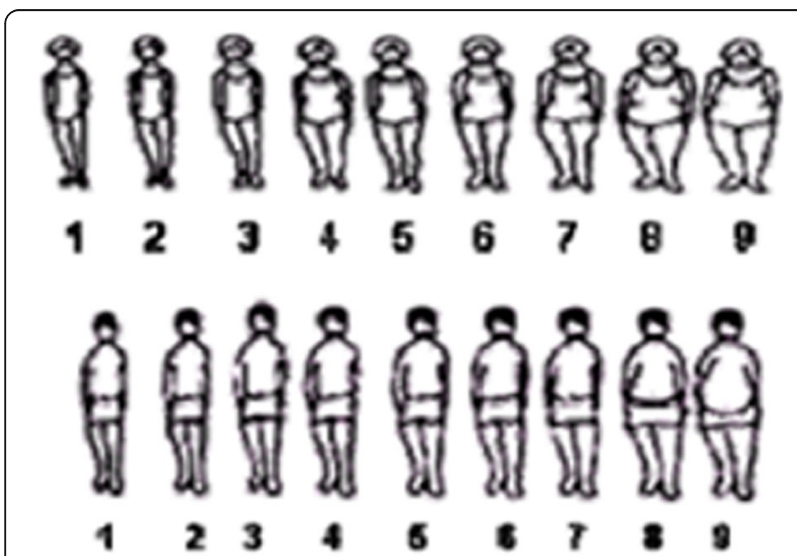

Fig. 1 The figure rating scale in the form of a nine-figure Stunkard scale as used in the ENSANUT 2006 questionnaire to test the self-perception in order to facilitate interpretation of the results. However, rather than only using the standard BMI categories eight BMI bins were created in order to have more discriminatory power as a function of BMI, while still maintaining a sufficiently large sample size in each bin. Thus, more/less bins means better/worse discrimination of the relation between actual and perceived BMI but worse/better statistical significance. Eight bins were chosen as a balance between these competing requirements. Due to the requirement of having the bins also respect the standard BMI categories it was not possible to guarantee equal sized bins for all, but the relative proportions ensure that each bin carries a substantial number for the analysis.

The average response to both BMI related questions were plotted with their standard error bars, for each of the four groups of gender and identification and for each of the eight BMI ranges. These graphs were used to visually assess the differences between identified and nonidentified and genders.

To statistically verify the difference between two slopes, in this case for the non-identified and the identified, the interaction term regression method was used $[35,36]$. By first calculating the slopes for the nonidentified and the identified separately, we carried out a multiple regression incorporating two terms: an interaction term for the identified that is created by multiplying a categorical variable by the dependent variable; and self-perception response. These are compared against the actual BMI and it is the interaction term that is used to test the null hypothesis. Provided that the results of this test prove that there is no difference in the slopes, a comparison of the constants in the regression analysis can be made in order to test the statistical significance of the difference in the responses between the identified and the non-identified obese. This method involves using a categorical variable to distinguish between the identified and the non-identified obese in the regression. Should the result of the categorical variable be significant within the multiple regression, this would prove that there is a significant difference in the constants and hence indicate that the shift in self-perception is constant, due to the parallel nature of the slopes.

It is possible to determine that the difference in mean perceived BMI, as proxied by the metric scales, corresponds to a given difference in the means of actual BMI. To do this, the average responses on the metric scales, [1-4] for the categorical question and [1-9] for the FRS, were compared to give a measure of change in perception as BMI increases. Across the BMI ranges we are considering, the change in perception was compared to the change in actual BMI. We then determine what this change in actual BMI represents in the self-perception question scales. For example, by definition, if perceived 
BMI were a faithful measure of actual BMI, the categorical question should show an increase in average response from 2 to 4 , as actual BMI increases from normal $(18.5 \leq \mathrm{BMI}<25$, represented as 2$)$ up to obese $(30 \leq \mathrm{BMI}$, represented as 4); an increase of two on the category scale. Similarly, for the FRS, an increase in actual BMI from normal to obese should correspond to an increase in figure response from 3-4 to 8-9. To convert the mean response into a measure of perceived BMI, we assume that the response scales are linear measures of BMI. By then carrying out a linear regression, the slope associated with perceived BMI was compared with the slope that best represents actual BMI change to determine the degree that differences in perception are an accurate estimate of real differences.

\section{Results}

The frequency of obesity in non-identified men and women was 19.62 and $31.39 \%$ respectively, as shown in the summary statistics in Table 1 . However, only 4.38 and $7.87 \%$ of men and women respectively had been identified by a healthcare professional as being obese. This corresponds to proportions of 18.94 and $21.38 \%$, for men and women, who had been identified among those who are obese or had been previously identified as such. Of the identified, we can see in Table 1 that only $6.24 \%$ of women and $3.68 \%$ of men currently had a normal BMI $(<25)$, while 24.71 and $30.88 \%$, respectively, changed from identified obese to actual overweight $(25 \leq \mathrm{BMI}<30)$.

As mentioned in the introduction, our hypothesis is that for both the men and women, there is a difference between the mean self-perception responses of a nonidentified obese and an identified obese Mexican adult, for each BMI range, due to the effect of a consultation to identify obesity with a medical professional. Therefore, there are four main categories that were compared, the first two relate to the difference between nonidentified and identified for the FRS for both men and women separately. The second two categories relate to the difference between the non-identified and the identified for the category self-perception question, again for men and women separately.

For each of the eight BMI ranges discussed in the methodology, and for both genders, the mean self-perception response was calculated for the non-identified and the identified. By taking the non-identified as the reference perspective, the comparison to identified adults would show the effect, if any exists, of identification. The results for the categorical opinion question can be seen in Fig. 2, with the results for the FRS in Fig. 3, where in both cases we have displayed the discrete, ordinal category and FRS variables as linear and metric.

In Fig. 2, we observed that the relationship between perceived BMI, as proxied by the category scale, and actual BMI is monotonic and non-linear, where the morbidly obese $(B M I \geq 35)$ did not show an increase in perceived BMI as a function of actual BMI irrespective of identification or gender.

We observed that the difference between responses for the identified and the non-identified is constant. This has been statistically confirmed by testing the null hypothesis that the slope for the non-identified is equal to the slope of the identified. The results for the analysis of the comparison of the two slopes for both, males $(p=$ $0.773)$ and females $(p=0.614)$, showed that the differences in the slopes of the identified and non-identified are not statistically significantly different, hence, we fail to reject the null hypothesis. Thus, the relative misperception of BMI, defined as selecting a category/figure that does not correspond to actual BMI, is to a large degree independent of actual BMI. We also saw a systematic difference between the average category rating of non-identified men and women, with women reporting a slightly higher mean category rating than men.

Furthermore, the results shown in Fig. 2 clearly showed that a consultation to identify obesity systematically changes the self-perceived weight categorisation of the adults in the data set. This is inclusive of men and women and across all BMI ranges. Given that there was no significant difference between the slopes, indicating that the lines are parallel, the effect of a consultation was verified by a comparison of the constants from the regressions for the identified and the non-identified obese. The results for male responses to the category question were weakly significantly different $(p=0.052)$, and the results for the women were significantly different $(p=0.018)$. Full details on the regression analysis for the identified and non-identified men and women related to the category question are included in Table 2.

In Fig. 3 we observed that average figure rating is also a monotonically increasing, non-linear function of actual

Table 1 Summary statistics for the population of 17009 adults taken from ENSANUT 2006

\begin{tabular}{|c|c|c|c|c|c|c|c|c|c|c|c|}
\hline \multicolumn{3}{|l|}{ NI Men } & \multicolumn{3}{|l|}{ I Men } & \multicolumn{3}{|c|}{ NI Women } & \multicolumn{3}{|c|}{ I Women } \\
\hline Normal & Over & Obese & Normal & Over & Obese & Normal & Over & Obese & Normal & Over & Obese \\
\hline 2219 & 2550 & 1164 & 10 & 84 & 178 & 3034 & 3795 & 3125 & 53 & 210 & 587 \\
\hline $37.40 \%$ & $42.98 \%$ & $19.62 \%$ & $3.68 \%$ & $30.88 \%$ & $65.44 \%$ & $30.48 \%$ & $38.13 \%$ & $31.39 \%$ & $6.24 \%$ & $24.71 \%$ & $69.06 \%$ \\
\hline
\end{tabular}

Primary categories are labelled by identification of obesity by a healthcare professional ( $\mathrm{NI}$ - Non-Identified obese and I - Identified obese) and gender (Men, Women). Further division is based on actual BMI, where Normal represents $18.5 \leq \mathrm{BMI}<25$, Over represents $25 \leq \mathrm{BMI}<30$ and Obese represents $\mathrm{BMI} \geq 30$ 


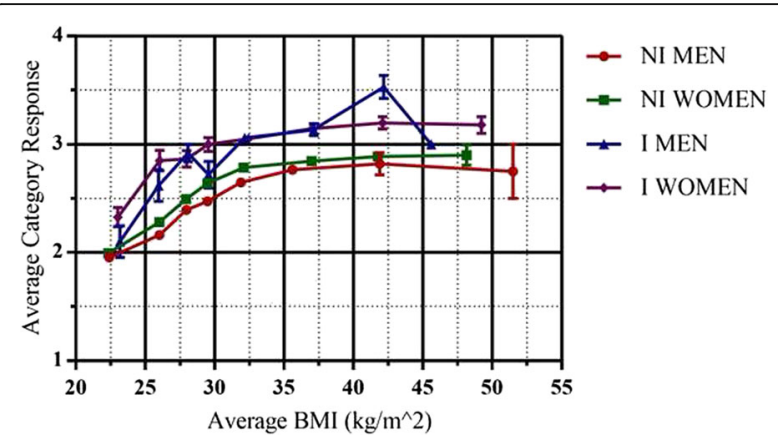

Fig. 2 A comparison of mean perceived BMI (categorical) versus actual BMl, grouped by gender and identification of obesity by a medical professional. Average category response: 1 - underweight, 2 - normal, 3 - overweight, 4 - obese. $\mathrm{NI}$ - Non-identified, I - Identified. Standard error bars for average category response are included for each point

BMI for all groups. The only exception was the identified men in the range $45 \leq \mathrm{BMI} \leq 60$, where there are only three participants. As with the category scale, the morbidly obese $(\mathrm{BMI} \geq 35)$ did not exhibit any increase in perceived BMI as actual BMI increased. Once again, this tendency was present for both identified and nonidentified and both genders.

Again, the difference in the identified and the nonidentified has been checked statistically via a comparison of the two slopes via an interaction term. For the FRS responses of both the males $(p=0.238)$, and the women $(p=0.815)$, the slopes of the non-identified and the identified were not statistically significantly different to each other, and thus the difference between identified and non-identified is constant. There was also a systematic difference by gender across both identification categories, with women being associated with a lower perceived $\mathrm{BMI}$ versus men for a given actual BMI.

We also saw that identification systematically changes the self-perception of both men and women on the FRS.

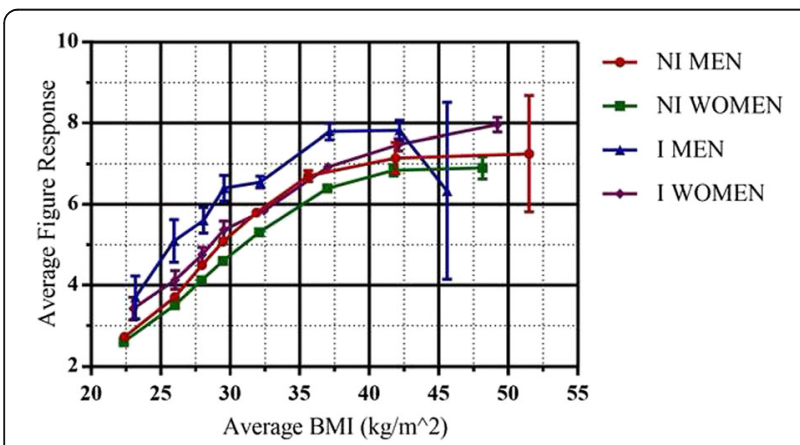

Fig. 3 A comparison of mean figure rating scale response versus actual $\mathrm{BMl}$, grouped by gender and identification of obesity by a medical professional. Average figure response from 1-9. NI - Non-identified, I - Identified. Standard error bars for average figure response are included for each point
The differences in self-perception responses for the FRS question between the identified and the non-identified have again been calculated using the comparison of constants in regression analysis. The comparison for identified and non-identified males showed that there was no significant difference across the full BMI range $(p=$ 0.191 ), however, this is due to the sudden drop in the final BMI group for the diagnosed males. Carrying out this method, but excluding the final BMI range for males gives a highly significant result $(p=0.004)$. The results for the women across the full BMI range also gave a significant result $(p=0.017)$. There was an average increase across all BMI ranges that was approximately one figure for the men, while the effect on the women was slightly less, confirming that the relative misperception of BMI is to a large degree independent of actual BMI. Full details on the regression analysis for the identified and non-identified men and women related to the FRS question are included in Table 3.

From Figs. 2 and 3 we observed visually that there was a substantial range of $\mathrm{BMI}, \mathrm{BMI}<38$ for the FRS and BMI $<32$ for the category question, over which the relationship between $\mathrm{BMI}$ and the corresponding integer-mapped metric scales for the category question and FRS were approximately linear. We investigated further the linearity of the curves, over the interval $\mathrm{BMI}<35$, by performing linear regressions - FRS/category response versus BMI-of the raw data for the following categories: All adults, all men, all women, all identified, all non-identified, identified men, non-identified men, identified women and nonidentified women. As necessary when using linear regression, the assumptions of a linear relationship between the two variables, a lack of outliers, independence of observations, homoscedacity and the residuals of the regression line being normally distributed were all checked and verified. SPSS Statistics 22 was used for all aspects of statistical analysis. The results can be seen in Table 2 for the category and in Table 3 for the FRS question.

Notably, for both figures and categories, we observed that all regressions were statistically significant, with f-statistics in the range 31.80-7573.01 and $\mathrm{t}$-statistics for the regression coefficients in the range 5.64-87.02, with lower values being associated with the identified, where the sample sizes were smaller.

\section{Discussion}

The relationship between perceived BMI and actual BMI exhibits some universal features across the two distinct self-perception questions. First of all, the monotonicity of the relations showed that, as would be hoped, on average, those who had greater BMI also perceived themselves to have greater BMI. Furthermore, over a substantial range of actual BMI the relation was approximately linear for both the FRS and the category scale. 
Table 2 Linear regression analyses of BMl versus category response for all gender/identification groupings for $\mathrm{BMI}<35$

\begin{tabular}{|c|c|c|c|c|c|c|c|c|c|}
\hline & Variable & Unstd. B & Std. Error & t-statistic & f-statistic & $R^{2}$ & Sig & 95\% C.I. Lower & 95\% C.I. Upper \\
\hline \multirow[t]{3}{*}{$\overline{\text { All }}$} & & & & & 5764.888 & 0.271 & 0 & & \\
\hline & Constant & 19.384 & 0.101 & 192.18 & & & 0 & 19.186 & 19.581 \\
\hline & Category & 3.224 & 0.042 & 75.927 & & & 0 & 3.141 & 3.307 \\
\hline \multirow[t]{3}{*}{ Men } & & & & & 2173.229 & 0.269 & 0 & & \\
\hline & Constant & 19.01 & 0.162 & 117.302 & & & 0 & 18.692 & 19.328 \\
\hline & Category & 3.303 & 0.071 & 46.618 & & & 0 & 3.164 & 3.442 \\
\hline \multirow[t]{3}{*}{ Women } & & & & & 3473.562 & 0.266 & 0 & & \\
\hline & Constant & 19.68 & 0.13 & 151.671 & & & 0 & 19.426 & 19.934 \\
\hline & Category & 3.15 & 0.053 & 58.937 & & & 0 & 3.045 & 3.255 \\
\hline \multirow[t]{3}{*}{$\mathrm{Nl}$} & & & & & 5826.474 & 0.268 & 0 & & \\
\hline & Constant & 18.255 & 0.125 & 146.304 & & & 0 & 18.01 & 18.499 \\
\hline & Category & 3.996 & 0.052 & 76.331 & & & 0 & 3.893 & 4.099 \\
\hline \multirow[t]{3}{*}{ Identified } & & & & & 93.45 & 0.109 & 0 & & \\
\hline & Constant & 24.302 & 0.591 & 41.146 & & & 0 & 23.143 & 25.462 \\
\hline & Category & 1.923 & 0.199 & 9.667 & & & 0 & 1.532 & 2.313 \\
\hline \multirow[t]{3}{*}{ Men NI } & & & & & 1916.112 & 0.251 & 0 & & \\
\hline & Constant & 19.119 & 0.167 & 114.695 & & & 0 & 18.792 & 19.445 \\
\hline & Category & 3.229 & 0.074 & 43.773 & & & 0 & 3.085 & 3.374 \\
\hline \multirow[t]{3}{*}{ Men I } & & & & & 29.848 & 0.127 & 0 & & \\
\hline & Constant & 24.214 & 1.083 & 22.351 & & & 0 & 22.078 & 26.25 \\
\hline & Category & 2.006 & 0.367 & 5.463 & & & 0 & 1.282 & 2.73 \\
\hline \multirow[t]{3}{*}{ Women NI } & & & & & 3092.896 & 0.255 & 0 & & \\
\hline & Constant & 19.685 & 0.134 & 146.771 & & & 0 & 19.422 & 19.948 \\
\hline & Category & 3.121 & 0.056 & 55.614 & & & 0 & 3.011 & 3.231 \\
\hline \multirow[t]{3}{*}{ Women I } & & & & & 64.919 & 0.103 & 0 & & \\
\hline & Constant & 24.31 & 0.702 & 34.624 & & & 0 & 22.931 & 25.689 \\
\hline & Category & 1.9 & 0.236 & 8.057 & & & 0 & 1.437 & 2.363 \\
\hline
\end{tabular}

In the Categories column the regression analyses are categorised by gender (All represents the combined group of men and women); and by identification of obesity (I and NI). Variable refers to the regression coefficients; Unstd. B Unstandardised Beta coefficient, Std. Error standard error, t-statistic, f-statistic, $\mathrm{R}^{2}$, Sig Significance value, $95 \%$ C.I. Lower Lower bound of the $95 \%$ confidence interval, $95 \%$ C.I. Upper Upper bound of the $95 \%$ confidence interval. Responses were taken only in the range $\mathrm{BMI}<35$ to test linearity

The question then becomes: Is the rate of increase of perceived BMI equal to the rate of increase of actual BMI? What would one expect as an appropriate rate of increase of perceived BMI as a function of actual BMI if there were no weight misperception? As stated, the standard categorisation of the Stunkard scale figures are as follows; $1-2=$ underweight, $3-4=$ normal, $5-7=$ over weight and $8-9=$ obese [34]. If we take the FRS to be a linear measure of BMI, one would expect BMI to increase from approximately 20 to approximately 30 as the FRS ranges from 3 to 8 , i.e., $2 \mathrm{kgm}^{-2}$ per unit increase in figure rating. If we conservatively consider only four figures to cover this BMI range, then one would determine $2.5 \mathrm{kgm}^{-2}$ per unit increase in figure rating. Similarly, if we consider a more extensive range of figures, say 6 , then one would expect a rate of change of $1.67 \mathrm{kgm}^{-2}$ per unit increase in figure rating. For the categorisation question, if the respondents perfectly classified their BMI status, then the normal group $(18.5 \leq \mathrm{BMI}<25)$ should have an average category rating of 2 , the overweight $(25 \leq \mathrm{BMI}<30)$ an average of three and the obese $(\mathrm{BMI} \geq 30)$ an average of 4 , i.e., a monotonic increase from 2 to 4 over the range $18.5 \leq \mathrm{BMI}<25$, corresponding to a slope of 5.75 .

In Fig. 3, and quantitatively in Table 3, we observed that the range of slopes across all groups is in the range 0.574-1.254. These values are far below what would be expected if BMI perceptions were faithfully following actual BMI. As the maximum slope corresponding to the $95 \%$ confidence intervals was 1.29 , we can state that 
Table 3 Linear regression analyses of BMI versus figure response for all gender/identification groupings for BMI < 35

\begin{tabular}{|c|c|c|c|c|c|c|c|c|c|}
\hline & Variable & Unstd. B & Std. Error & t-statistic & f-statistic & $R^{2}$ & Sig & 95\% C.I. Lower & 95\% C.I. Upper \\
\hline \multirow[t]{3}{*}{$\overline{\text { All }}$} & & & & & 7573.014 & 0.328 & 0 & & \\
\hline & Constant & 22.306 & 0.057 & 388.213 & & & 0 & 22.193 & 22.148 \\
\hline & Figure & 1.13 & 0.013 & 87.023 & & & 0 & 1.104 & 1.155 \\
\hline \multirow[t]{3}{*}{ Men } & & & & & 2736.797 & 0.316 & 0 & & \\
\hline & Constant & 22.395 & 0.085 & 262.99 & & & 0 & 22.228 & 22.561 \\
\hline & Figure & 0.982 & 0.019 & 52.314 & & & 0 & 0.945 & 1.019 \\
\hline \multirow[t]{3}{*}{ Women } & & & & & 5126.825 & 0.348 & 0 & & \\
\hline & Constant & 22.132 & 0.076 & 290.36 & & & 0 & 21.983 & 22.281 \\
\hline & Figure & 1.252 & 0.017 & 71.602 & & & 0 & 1.218 & 1.287 \\
\hline \multirow[t]{3}{*}{$\mathrm{Nl}$} & & & & & 6920.629 & 0.319 & 0 & & \\
\hline & Constant & 22.267 & 0.058 & 380.662 & & & 0 & 22.152 & 22.381 \\
\hline & Figure & 1.12 & 0.013 & 83.19 & & & 0 & 1.094 & 1.147 \\
\hline \multirow[t]{3}{*}{ Identified } & & & & & 168.078 & 0.18 & 0 & & \\
\hline & Constant & 26.031 & 0.318 & 81.938 & & & 0 & 25.407 & 26.655 \\
\hline & Figure & 0.712 & 0.055 & 12.964 & & & 0 & 0.604 & 0.819 \\
\hline \multirow[t]{3}{*}{ Men NI } & & & & & 2492.355 & 0.304 & 0 & & \\
\hline & Constant & 22.402 & 0.086 & 260.267 & & & 0 & 22.234 & 22.571 \\
\hline & Figure & 0.964 & 0.019 & 49.923 & & & 0 & 0.927 & 1.002 \\
\hline \multirow[t]{3}{*}{ Men I } & & & & & 31.447 & 0.132 & 0 & & \\
\hline & Constant & 26.551 & 0.65 & 40.817 & & & 0 & 25.269 & 27.834 \\
\hline & Figure & 0.574 & 0.102 & 5.608 & & & 0 & 0.372 & 0.776 \\
\hline \multirow[t]{3}{*}{ Women NI } & & & & & 4706.297 & 0.342 & 0 & & \\
\hline & Constant & 22.053 & 0.078 & 282.442 & & & 0 & 21.9 & 22.206 \\
\hline & Figure & 1.254 & 0.018 & 68.602 & & & 0 & 1.218 & 1.29 \\
\hline \multirow[t]{3}{*}{ Women I } & & & & & 140.332 & 0.201 & 0 & & \\
\hline & Constant & 25.759 & 0.369 & 69.77 & & & 0 & 25.033 & 26.484 \\
\hline & Figure & 0.786 & 0.066 & 11.846 & & & 0 & 0.656 & 0.917 \\
\hline
\end{tabular}

In the Figures column the regression analyses are categorised by gender (All represents the combined group of men and women); and by identification of obesity (I and NI). Variable refers to the regression coefficients; Unstd. B Unstandardised Beta coefficient, Std. Error standard error, $\mathrm{t}$-statistic, $\mathrm{f}$-statistic, $\mathrm{R}^{2}$, Sig Significance value, 95\% C.I. Lower Lower bound of the 95\% confidence interval, 95\% C.I. Upper Upper bound of the 95\% confidence interval. Responses were taken only in the range BMI < 35 to test linearity

no slope is consistent with any of the null hypotheses of $1.67,2$ or $2.5 \mathrm{kgm}^{-2}$ per unit change in figure rating. Thus, we saw that the relative misperception of BMI, understood as the difference between the change in perceived BMI per unit increment in actual BMI, was fairly constant over a substantial range. Indeed, in the case of the FRS, the linearity extended to the onset of morbid obesity (BMI $\geq 35)$. Beyond this point, the increase in perceived BMI per unit increase in actual BMI decreased even further, such that there was only a very small increase in perceived BMI - approximately one figure rating unit - over a very wide range, $35 \leq \mathrm{BMI}<50$.

For the categorical question, the expected slope is 5.75 while, as we can see in Table 2, the observed slopes were in the range 1.9 to 4 , i.e., between 67 and 30\% less. Once again, there was a qualitative change in behaviour around the onset of morbid obesity. In the context of the categorical question, this is an indication that the proportion of morbidly obese respondents, who consider themselves to be obese, is small. In fact, in the BMI ranges $35 \leq \mathrm{BMI}<40,40 \leq \mathrm{BMI}<45$ and $45 \leq \mathrm{BMI} \leq 60$, the fractions that considered themselves to be obese were only $6.69,11.04$ and $13.95 \%$ respectively.

The large discrepancy between the slope of the expected relation between perceived and actual BMI and the actual relation is a clear indication that there is a large misperception between perceived and actual BMI differences. A given BMI increment was perceived as between 25 and $77 \%$ less than its real value, the precise value depending on how a figure rating increment, or category increment, is translated into a perceived BMI increment and which subgroup we consider. The 
principal implication is that any given BMI increase is perceived as considerably less than it really is. Misperception of BMI has standardly been emphasized with respect to the misperception of the obese and overweight. What we have demonstrated here is that our results are consistent with a relative misperception of BMI that is both large and independent of BMI over a substantial BMI range.

Why could relative misperception of BMI be constant? We believe that the universal form of the relationship between perceived and actual BMI, is an important indicator of the underlying psychology of weight perception and hypothesise that it is linked to the self-serving bias [37], a well-established cognitive bias strongly linked to self-esteem. This self-serving bias acts, we argue, to consistently underestimate BMI increments independently of actual BMI.

A further notable feature of Figs. 2 and 3, seen in detail in Tables 2 and 3, is the difference in perception between the non-identified and the identified and between genders. Within our linear approximation, such differences in perception manifest in differences in the regression coefficients - either the slope or the constant. From Table 3, we saw that the difference in constants, 22.27 versus 26.31 , was statistically significant between the identified and non-identified, as is the difference between the slopes, 1.12 versus 0.712 . These conclusions are also valid when comparing both identified and nonidentified men and women as a sub-category. For the categorical question, we also saw that there is a noticeable difference between the identified and non-identified by gender. Interestingly, there was no statistically significant difference in either intercept or slope between identified women and identified men. Similarly, there was no statistically significant difference between the intercepts for non-identified men and women but there was between slopes. It is worth noting that across every pair of comparable categories the intercept of the identified was greater than that of the non-identified and the slope less. Thus, we can see that identification of obesity is consistent with a shift in perception that manifests itself principally as a constant shift in perceived BMI. This was seen most clearly for $\mathrm{BMI}<25$, where it was associated with a difference of $3-4 \mathrm{kgm}^{-2}$ for the same figure rating. In this regime, it is clearly identifiable as an overassessment of BMI of the identified relative to the nonidentified. However, as the regression coefficients were less for an identified group than the corresponding nonidentified group it implies that the identified perceived an actual BMI change as being less than that perceived by the non-identified.

We propose that this change can be understood in terms of another cognitive bias - anchoring [38] - that occurs when individuals use an "initial" piece of information in making subsequent judgments. If an anchor has been set, then judgments are biased in that they adjust away from that anchor. We propose that identification acts as an anchor, from which subsequent self-perception of BMI is measured. Thus, anchoring is a natural explanation of the offset between the identified and the non-identified curves in the figures and is additional to the self-serving bias, which we claim is an important element in the shape of the curves. It is also consistent with the smaller perceived effect of a BMI change for the identified if we take the anchoring effect as to anchor the identified to the obese category, therefore perceiving weight loss in terms of figure ratings to be less than it actually is.

It has been argued that identification leads to a more accurate self-perception of BMI, in the case of the obese $[17,29]$. However, it has also been shown that overassessment of weight is prevalent [13]. Above, we argued that an identification of obesity has the effect of increasing the degree of over-assessment of weight given that only $8.91 \%$ of the non-identified with $\mathrm{BMI}<25$ considered themselves to be overweight or obese, with the corresponding figure for the identified being $36.51 \%$. This is consistent with what is observed in Figs. 2 and 3. Thus, we assert that identification does not lead to a superior capacity to assess BMI per se but, rather, simply leads to a different anchoring point from which BMI is assessed. The apparent improvements in perception of BMI associated with higher fractions of the obese recognising their obese status after an identification we would argue relates to the anchoring effects of the identification coupled with the fact that so few obese return to a normal weight. A more accurate self-perception of body weight and BMI and, importantly, changes in bodyweight, would be very advantageous in the fight against obesity. Here the belief is that while it is not guaranteed to result in action, knowledge and acceptance of a problem is the crucial first step to making a change.

The final difference we note is that between genders. This was seen in Tables 2 and 3, where we noticed that the slopes for women were statistically significantly greater than those for men in the case of the nonidentified. Thus, non-identified women/men over-assess/ under-assess their weight relative to men/women. This relative over-assessment of weight reduces as a function of BMI, exhibiting the fact that non-identified women perceived a given BMI increment as being bigger than that perceived by a non-identified man. For the category question there were no statistically significant differences between identified/non-identified men and women.

Some potential limitations of this research are: i) the data is cross-sectional, thereby making causal inference more difficult; this is particularly the case in that we are considering BMI differences across different group not 
across a cohort of the same individuals; ii) the male/female ratio for the ENSANUT respondents is skewed and therefore not fully representative of the Mexican population; iii) identification of obesity by a healthcare professional was self-reported and therefore subject to recall and other biases; iv) Weight categories are defined using standard BMI cut-off points and these are potentially unknown to most respondents; v) We assume that no other variable distinguishes the identified from the nonidentified, e.g. socio-economic category etc. However, we checked explicitly that the age distribution was the same; vi) We have assumed that the Stunkard scale and the category scale can be interpreted as approximately linear measures of BMI.

\section{Conclusions}

An impressive aspect of the obesity epidemic is its universality-crossing gender, racial, genetic and cultural boundaries, to name but a few - the differences between these groups being notably smaller than the overall effect. Although obesity is a highly multi-factorial problem, this hints at the fact that universal tendencies exist, which are to a large degree independent of these factors. We suggest that various cognitive biases could be one source of such tendencies and therefore could play a potentially important role in the obesity epidemic. Here, we have mentioned two: the self-serving bias and anchoring bias; that we argue could be responsible for our results. Recent results have also commented on these cognitive biases for self-perception but in relation to the ENSANUT 2012 database [39].

We believe that the results we have shown have important ramifications for public health interventions. It is accepted that an important step for implementing a weight loss program is for the person to accept their obese status and, preferably, to accept it as a serious condition. In this case, emphasis is squarely placed on the concept of weight/BMI status and its recognition. Misperception of BMI is then a severe obstacle to this goal. There is, however, no clear evidence that such identifications lead to long-term reductions in BMI through weight reduction when compared to the nonidentified. The difficulty of returning to a normal weight from obesity have recently been emphasised by Fildes et al. [40], where over a 9 -year period $3.1 \%$ of obese $(30 \leq \mathrm{BMI}$ $<35)$ men and $5.1 \%$ of obese women returned to a normal BMI. These numbers are consistent with our results, 3.68 and $6.24 \%$ respectively, in that they show the immense challenges associated with returning to a healthy BMI.

We believe that the public health message of this paper is, rather, that the most important impact of misperceptions of BMI is not in gauging BMI state but in terms of perceiving and gauging changes, both positive and negative, in BMI. Uniformly, BMI changes are underestimated, with the identified being particularly susceptible. For instance, an actual BMI increment of $2 \mathrm{kgm}^{-2}$ may be perceived to be an increment of just half that value. Thus, the real danger is in underestimating weight increases until it is too late. This is consistent with a preventative approach, implementing wide-ranging screening to detect those whose BMI has increased substantially.

\begin{abstract}
Abbreviations
BMI: Body mass index; ENSANUT: National Survey of Health and Nutrition [from "Encuesta Nacional de Salud y Nutrición" in Spanish]; FRS: Figure rating scale; I: Identified; NI: Non-identified
\end{abstract}

\section{Acknowledgements}

The authors are grateful for very useful discussions with Katherine Stephens on cognitive biases.

\section{Funding}

This work was supported by the Universidad Nacional Autonoma de Mexico DGAPA Programa de Apoyo a Proyectos de Investigación e Innovación Tecnológica (PAPIIT) grant number: IN113414, CONACyT project 155663 and CONACyT Fronteras de la Ciencia grant FC-2015-2/1093.

\section{Availability of data and materials}

As is required by BMC standards, the authors certify that all data used for the purposes of the study being reported in the manuscript titled "The Effect of a Medical Opinion on Self-perceptions of Weight for Mexican Adults: Perception of Change and Cognitive Biases" is secondary data which is available to all researchers interested in the data for their own experiments. The data is freely available from the 'Instituto Nacional de Salud Publica' of Mexico, and can be obtained by accessing the institute's website and completing the registration form found in the following link: http://ensanut.insp.mx/ forma_registro.php.

\section{Authors' contributions}

All authors certify that the work is original and their own. All authors approve of the manuscript and its submission for publication, where there contributions and work are as follows: JFE and CRS designed and conceived the investigation; JFE and HRS worked with the data and carried out statistical analysis; JFE, CRS and HRS participated in results interpretation and discussion; JFE and CRS wrote the manuscript; JFE, CRS and HRS revised the manuscript and approved the final version.

\section{Competing interests}

The authors declare that they have no competing interests.

\section{Consent for publication}

Not applicable.

\section{Ethics approval and consent to participate}

This research uses secondary data which has not been collected by any of the authors. All ethics and consent had previously been approved before being accessed for use in this research. For more information on the ethics for this data please contact the 'Comité de Etica del Instituto Nacional de Salud Pública'.

\section{Publisher's Note}

Springer Nature remains neutral with regard to jurisdictional claims in published maps and institutional affiliations.

\section{Author details}

${ }^{1}$ C3-Centro de Ciencias de la Complejidad, Universidad Nacional Autónoma de México, Circuito Centro Cultural s/n, Ciudad Universitaria, Col. Universidad Nacional Autónoma de México, Del. Coyoacán, C.P. 04510 Ciudad de México, Mexico. ${ }^{2}$ Instituto de Ciencias Nucleares, Universidad Nacional Autónoma de México, Circuito Exterior s/n, Ciudad Universitaria, Col. Universidad Nacional Autónoma de México, Del. Coyoacán, A. P. 70-543, C.P. 04510 Ciudad de México, Mexico. 
Received: 24 May 2016 Accepted: 17 March 2017 Published online: 03 May 2017

\section{References}

1. Food and Agriculture Organization of the United Nations (FAO) [Internet]. [place unknown]. FAO. 2013. The State of Food and Agriculture. Available from: http://www.fao.org/docrep/018/i3300e/i3300e.pdf. cited 4 Sept 2015.

2. Organization for Economic Cooperation and Development (OECD) [Internet]. [place unknown]. OECD. 2014. Obesity and the economics of prevention: Fit not fat. Key Facts - Mexico, Update 2014. Available from: http://www.oecd.org/mexico/Obesity-Update-2014-MEXICO_EN.pdf. cited 4 Sept 2015.

3. Frühbeck G, Toplak H, Woodward E, Yumuk V, Maislos M, Oppert JM. Obesity: the gateway to ill health - an EASO position statement on a rising public health, clinical and scientific challenge in Europe. Obes Facts. 2013; 6(2):117-20

4. Kopelman PG. Obesity as a medical problem. Nature. 2000;404(6778):635-43.

5. Beauchamp A, Backholer K, Magliano D, Peeters A. The effect of obesity prevention interventions according to socioeconomic position: a systematic review. Obes Rev. 2014;15(7):541-54.

6. Dombrowski SU, Knittle K, Avenell A, Araujo-Soares V, Sniehotta FF. Long term maintenance of weight loss with non-surgical interventions in obese adults: systematic review and meta-analyses of randomised controlled trials. BMJ. 2014;348:92646.

7. Fiona J, Rebecca JB, Helen C, Wardle J. Do weight perceptions among obese adults in Great Britain match clinical definitions? Analysis of crosssectional surveys from 2007 and 2012. BMJ Open. 2014:4:e005561. doi:10.1136/bmjopen-2014-005561.

8. Aditya B, Shernan GH, Jeffrey MS, Warren GT. Diagnosis of obesity by primary care physicians and impact on obesity management. Mayo Clin Proc. 2007:82(8):927-32.

9. Sarah EJ, Jane W, Fiona J, Nicholas F, Rebecca JB. The impact of a health professional recommendation on weight loss attempts in overweight and obese British adults: a cross-sectional analysis. BMJ Open. 2013;3:e003693. doi:10.1136/bmjopen-2013-003693.

10. Mikolajczyk RT, Maxwell AE, El Ansari W, Stock C, Petkeviciene J, GuillenGrima F. Relationship between perceived body weight and body mass index based on self-reported height and weight among university students: a cross-sectional study in seven European countries. BMC Public Health. 2010;10(1):40.

11. Johnson-Taylor WL, Fisher RA, Hubbard VS, Starke-Reed P, Eggers PS. The change in weight perception of weight status among the overweight: comparison of NHANES III (1988-1994) and 1999-2004 NHANES. Int J Behav Nutr Phys Act. 2008;5(1):9.

12. Kamel EG, McNeill G. Men are less aware of being overweight than women. Obes Res. 2000;8(8):604.

13. Kuchler F, Variyam JN. Mistakes were made: misperception as a barrier to reducing overweight. Int J Obes Relat Metab Disord. 2003;27(7):856-61.

14. Yaemsiri S, Slining MM, Agarwal SK. Perceived weight status, overweight diagnosis, and weight control among US adults: the NHANES 2003-2008 study. Int J Obes. 2010;35(8):1063-70.

15. Cheung PC, Ip PL, Lam ST, Bibby H. A study on body weight perception and weight control behaviours among adolescents in Hong Kong. Hong Kong Med J. 2007:13(1):16.

16. Paeratakul S, White MA, Williamson DA, Ryan DH, Bray GA. Sex, Race/ Ethnicity, Socioeconomic Status, and BMI in Relation to Self-Perception of Overweight. Obes Res. 2002;10(5):345-50.

17. Arantxa Colchero M, Caro-Vega Y, Kaufer-Horwitz M. Socioeconomic status and misperception of body mass index among Mexican adults. Salud Publica Mex. 2014;56(3):251-8.

18. Andrade FCD, Raffaelli M, Teran-Garcia M, Jerman JA, Garcia CA, Up Amigos 2009 Study Group. Weight status misperception among Mexican young adults. Body Image. 2012;9(1):184-8.

19. Ruiz-Arregui L, Castillo-Martínez L, Orea-Tejeda A, Mejía-Arango S, MiguelJaimes A. Prevalence of self-reported overweight-obesity and its association with socioeconomic and health factors among older Mexican adults. Salud Publica Mex. 2007:49:s482-7.

20. Guendelman S, Ritterman-Weintraub ML, Fernald LC, Kaufer-Horwitz M. Weight Perceptions Among Overweight and Obese Women: A US-Mexico Binational Perspective. Obesity (Silver Spring). 2011;19(12):2440-3.
21. Guendelman SD, Ritterman-Weintraub ML, Fernald LC, Kaufer-Horwitz M Weight Status of Mexican Immigrant women: a comparison with women in Mexico and with US-born Mexican American women. Am J Public Health. 2013;103(9):1634-40.

22. Guendelman S, Ritterman-Weintraub ML, Haskin Fernald LC, Kaufer-Horwitz M. A population-based comparison of weight and weight perceptions among overweight and obese Mexican and Mexican-American men. Salud Publica Mex. 2013;55:5451-8.

23. Duncan DT, Wolin KY, Scharoun-Lee M, Ding EL, Warner ET, Bennett GG. Does perception equal reality? Weight misperception in relation to weightrelated attitudes and behaviors among overweight and obese US adults. Int J Behav Nutr Phys Act. 2011;8(1):20.

24. Jones M, Grilo CM, Masheb RM, White MA. Psychological and behavioral correlates of excess weight: Misperception of obese status among persons with Class II obesity. Int J Eat Disord. 2009;43(7):628-32.

25. Edwards NM, Pettingell S, Borowsky IW. Where perception meets reality: selfperception of weight in overweight adolescents. Pediatrics. 2010;125(3):e452-8.

26. Skinner AC, Weinberger M, Mulvaney S, Schlundt D, Rothman RL. Accuracy of perceptions of overweight and relation to self-care behaviors among adolescents with type 2 diabetes and their parents. Diabetes Care. 2008;31(2):227-9.

27. Mueller KG, Hurt RT, Abu-Lebdeh HS, Mueller PS. Self-perceived vs actual and desired weight and body mass index in adult ambulatory general internal medicine patients: a cross sectional study. BMC Obes. 2014;1(1):1-9.

28. Janz NK, Champion VL, Strecher VJ. The Health Belief Model. In: Health Behavior and Health Education: Theory, Research, and Practice. 3rd ed. San Francisco: Jossey-Bass; 2002. p. 45-66.

29. Post RE, Mainous 3rd AG, Gregorie SH, Knoll ME, Diaz VA, Saxena SK. The influence of physician acknowledgment of patients' weight status on patient perceptions of overweight and obesity in the United States. Arch Intern Med. 2011;171(4):316-21.

30. Pollak Kl, Alexander SC, Coffman CJ, Tulsky JA, Lyna P, Dolor RJ, et al. Physician communication techniques and weight loss in adults: Project CHAT. Am J Prev Med. 2010;39(4):321-8.

31. Olaiz-Fernández G, Rivera-Dommarco J, Shamah-Levy T, Rojas R, VillalpandoHernández S, Hernández-Avila M, et al. Encuesta Nacional de Salud y Nutrición 2006. 1st ed. Cuernavaca: Instituto Nacional de Salud Pública; 2006.

32. Stunkard AJ, Sørensen T, Schulsinger F. Use of the Danish Adoption Register for the study of obesity and thinness. Res Publ Assoc Res Nerv Ment Dis. 1983;60:115.

33. Stunkard AJ. Old and new scales for the assessment of body image. Percept Mot Skills. 2000;90(3):930.

34. Bhuiyan AR, Gustat JR, Srinivasan SR, Berenson GS. Differences in Body Shape Representations among Young Adults from a Biracial (Black-White), Semirural Community: The Bogalusa Heart Study. Am J Epidemiol. 2003;158(8):792-7.

35. Keppel G, Wickers T. Design and analysis: A researcher's handbook, 4th edn. Pearson, United States; 2004

36. Hamilton LC. Regression with graphics: A second course in applied statistics. Duxbury press, Belmont, United States; 1992.

37. Forsyth D. Self-Serving Bias. In: International Encyclopedia of the Social Sciences. 2nd ed. Macmillan Reference; Detroit, USA, 2008.

38. Wilson TD, Houston CE, Etling KM, Brekke N. A new look at anchoring effects: Basic anchoring and its antecedents. J Exp Psychol Gen. 1996;125(4):387-402.

39. Easton JF, Stephens CR, Sicilia HR. An analysis of real, self-perceived, and desired BMl: Is there a need for regular screening to correct misperceptions and motivate weight reduction? Front Public Health. 2017;5:12. doi:10.3389/fpubh.2017.00012.

40. Fildes A, Charlton J, Rudisill C, Littlejohns P, Prevost AT, Gulliford MC Probability of an obese person attaining normal body weight: cohort study using electronic health records. Am J Public Health. 2015;105(9):e54-9. 